\title{
Debt Maturity and the Use of Interest Rate Derivatives by Nonfinancial Firms
}

\author{
George W. Fenn \\ Mitch Post \\ Steven A. Sharpe
}

\author{
Capital Markets Section \\ Federal Reserve Board \\ 20th and C Sts., N.W. \\ Washington, D.C. 20551 \\ (202)452-3634
}

First Version: January 1996

This Version: August 1996

\begin{abstract}
We develop and test a simple model of a firm's optimal debt maturity and its demand for interest rate swaps using 1994 data of over 4000 nonfinancial corporations. As in other models of derivative use, ours predicts a systematic relationship between a firm's swap position and the interest-sensitivity of its cash flow. We test this by estimating the cross-sectional relationship between a firm's swap position and: (1) the amount of short-term and floating-rate debt in its capital structure; and (2) the interest-sensitivity of its EBIT. We find strong evidence that firms use swaps to hedge interest rate risk arising from their debt obligations but little evidence that they hedge interest rate risks arising from operating income. Consistent with theories of swap use (Arak et al., 1988, Wall, 1989, and Titman, 1992), our model also predicts that firms that avoid using swaps because of "transactions costs" issue less short-term debt than swap users, since the former are unable to hedge the resulting interest rate risk. We find this to be the case.
\end{abstract}

The views expressed herein are those of the authors' and do not necessarily reflect the views of the Board nor the staff of Federal Reserve System. We thank Chris Culp and participants at the Federal Reserve Board's Wednesday Lunch Workshop for helpful comments, and Mike Bowman and Doug Carson for superb research assistance. 


\section{Introduction}

The growth of derivatives markets has provided businesses with an expanded set of instruments for managing financial risk and, in theory, for enhancing their ability to optimize operating and financial strategies. In this paper, we develop a structural empirical model, broadly consistent with the existing body of theory on derivative use, of how firms ought to use interest rate derivatives in conjunction with their debt maturity structure to minimize capital costs while managing interest rate risk. To test the various predictions of our model, we put together a comprehensive dataset detailing firms' reported use of interest rate derivatives in 1994, including details on the types and amounts used, for a universe of over 4000 companies.

Our model is motivated by theories suggesting that the essential role of interest rate derivatives--and swaps in particular--is to permit firms to decouple their choice of debt maturity and interest rate exposure (Arak et al., 1988, Wall, 1989, and Titman, 1992). For example, some firms may find long-term debt to be a relatively expensive financing option, either because they have significant "growth options" that can give rise to underinvestment costs (Myers, 1977), or because they have favorable private information about future profitability (Flannery, 1986, and Diamond, 1991). Such firms can issue short-term debt yet avoid interest rate risk by hedging it away in the swap market. Conversely, firms that are particularly vulnerable to inefficient liquidation (Sharpe, 1991 and Diamond, 1991) can issue mostly long-term debt and, if they desire, swap some back into a floating-rate obligation. ${ }^{1}$

Our model incorporates both hedging motives for using derivatives, such as the desire to minimize fluctuations in earnings or cash flow (e.g., Smith and Stulz, 1985, Froot, Scharfstein, and Stein, 1993, and Demarzo and Duffie, 1995), as well as speculative motives-the desire to take a position based on expectations about interest rates. It also allows for fixed costs of using derivatives, an assumption that is consistent with previous findings that only a minority of firms--predominantly large firms--actually use them. This allows us to

\footnotetext{
${ }^{1}$ A firm might wish to swap a fixed-rate obligation into a floating-rate obligation in order to offset a positive correlation between its operating income and interest rates, so as to leave the firm's overall cash flow uncorrelated with interest rates. Alternatively, the firm may wish to "take a position" on interest rates; in particular, it may believe that future short-term rates will be lower than implied by current forward rates.
} 
characterize how the firm's endogenous decision to use interest rate derivatives interacts with its choice of debt maturity structure.

A key prediction of our model is that each firm's swap position is the sum of a hedging component that fully hedges that firm against fluctuations in interest rates, and a speculative component that is a function of a firm's view about interest rates. ${ }^{2}$ We test our model by regressing a firm's swap position on a set of variables that measure the firm's exposure to interest rate risk from different sources. This provides a simple way of investigating both the fraction of each source of interest rate risk that firms hedge (the regression coefficients) and the extent to which variations in swap positions can be accounted for by variations in exposure to interest rate risk (the regression r-squared). In theory, the unexplained variation in firm swap position represents idiosyncratic non-hedging swap activity.

Using this approach, we find strong evidence that firms employ interest rate swaps to hedge interest rate risk arising from their short-term debt obligations. The regression coefficient on the short-term debt variable in our swap regressions range between half to three-quarters of the theoretically predicted value of unity; moreover, the debt variable accounts for a substantial portion of the cross-sectional variation in swap positions.

In marked contrast, we find no evidence that firms hedge their "economic exposure" to interest rate risk---the risk implied by the correlation of their operating earnings, or cash flow before interest expense, with interest rates. In other words, empirically, this correlation provides little or no explanatory power for firm swap positions. Taken at face value, this result implies that firms do not hedge this source of interest rate risk. Although measurement error may partly account for our results, they are consistent with the responses to recent surveys in which firms report that they primarily hedge firm commitments (e.g. debt) or anticipated commitments, and, to a much lesser extent, economic exposure (Bodnar et al.

${ }^{2}$ Full hedging is the result of various assumptions we make, including concavity of the firm's objective function, perfect correlation between swaps and the firm's risk exposure, and no variable swap costs. 
(1995) and Phillips (1995)). ${ }^{3}$

A second implication of our model is that there should be systematic differences in the debt maturity of firms that use swaps and firms that avoid using swaps owing to "transactions costs". ${ }^{4}$ In particular, swap users ought to employ more short-term debt than nonusers with similar characteristics. Intuitively, swap users face a lower marginal cost of short-term debt because they do not bear its volatility cost. As predicted, we find that swap users issue more short-term debt than nonusers, and the difference is economically as well as statistically significant. A related implication is that the choice of debt maturity by swap users should be more sensitive to variables that serve as proxies for the agency and signalling costs of debt. This is because the debt maturity of swap users is chosen solely to minimize agency and signalling costs, whereas the debt maturity of nonusers is influenced both by these concerns as well by the firm's desired exposure to interest rate risk. Our results provide support for this prediction as well.

A third set of tests suggested by our model involves regressing a firm's swap position on the financial characteristics used to explain differences in desired debt maturity. In essence, the model and the results cited above suggest that, through their influence on optimal debt maturity, such characteristics determine a firm's desired swap position. Indeed, if debt maturity was perfectly observable, and if the relationship between a firm's debt maturity and these characteristics was truly linear, they would have the same explanatory power as debt maturity in a swap regression; moreover, the coefficient estimates on these characteristics in a swap regression would simply mirror the respective coefficient estimates in a debt maturity regression.

For a number of reasons, however, observable measures of debt maturity are, at best, noisy measures of a firm's true debt maturity (Barclay and Smith, 1995); in this case, firm financial characteristics may better "predict" swap positions than the debt structure variable

\footnotetext{
${ }^{3}$ One explanation for such behavior may be that firms, like researchers, have difficulty estimating economic exposure.

${ }^{4}$ In our model, all firms realize gross benefits from using swaps; however, certain firms are "nonusers" because the fixed costs of using swaps exceed the benefits.
} 
itself. Indeed, this is what we find: the adjusted $-\mathrm{R}^{2} \mathrm{~s}$ from regressions of a firm's swap position on these exogenous characteristics are nearly double those from regressions of swap positions on debt structure. Moreover, the regression coefficients conform closely to those suggested by theoretical models of debt maturity.

Our paper adds substantially to the literature on derivative use in several ways. It does so first by quantifying the amount of risk that firms hedge. The only other study to quantify hedging is Tufano (1996). For a sample of gold producers, he constructs a detailed measure of the fraction of estimated gold production that is sold forward through financial contracts. Most empirical studies of corporate derivative use (e.g., Nance, Smith, and Smithson, 1993, Dolde, 1995, Tufano, 1996 and Geczy, Minton, and Schrand, 1995) are concerned directly with testing alternative theories of why firms hedge, and focus only indirectly on the types and amount of risk that are hedged. ${ }^{5}$ Geczy, Minton, and Strand (1995) and Dolde (1995), for example, construct measures of a firm's operating exposure to interest rates, foreign exchange rates, and commodity prices, and generally find a positive relationship between risk exposure and derivative use; however they do not measure the fraction of a firm's exposure that is offset.

A second contribution of this paper is to focus explicitly on multiple sources of risk. Academic discussions of hedging often draw no distinction among different channels through which a given type of risk arises. The standard view--a view embodied by our own model--is that firms should be as concerned about the interest rate risk arising from their operations as they are about the risk arising from their debt obligations. Yet there are a number of reasons why firms might actually treat these sources of risk differently. The first we have already mentioned: debt-related interest rate exposure is easily measured whereas operating exposure must be estimated; thus, in one case firms are hedging a relatively certain risk, whereas in the

\footnotetext{
${ }^{5}$ Typically, these studies correlate the choice to use (or not to use) derivatives with various operating and financial characteristics. On balance, this line of research shows that size is an important determinant of derivative use, suggesting that firms must overcome certain fixed costs before using derivatives. These likely include the expense of hiring individuals with the skills necessary to design and implement a risk-management program, and the resources required for senior management to effectively monitor the firm's derivatives activities. Also, firms with a greater likelihood of financial distress or with significant growth options are more prone to derivative use.
} 
other case they are hedging an uncertain risk. A second reason relates to internal controls. Management may limit the use of derivatives to hedging debt obligations (and other contractual exposures) because speculation, disguised as hedging of operational exposure, is difficult to monitor. A third reason is accounting related. Derivatives used to hedge debt obligations and other contractual exposures may be eligible for hedge accounting treatment, whereas other derivatives must be marked to market. By estimating the extent to which hedge ratios vary across different sources of interest rate risk, we are able to shed some light on this issue.

Finally, none of the other empirical studies examines how the choice of using derivatives influences operating or financial strategies, a major focus of our study. By focusing on one such interaction, we highlight a specific channel through which derivative use may actually increase a firm's real cash flows: by permitting firms to obtain a lower-cost source of financing without regard to interest rate risk. Our approach could be extended to investigate the influence of derivative use on other operational and financial decisions, such as leverage and investment.

The remainder of the paper is organized as follows. In section 2 we develop a simple model of hedging behavior in which a firm simultaneously chooses the type of debt to issue and its swap position and describe its major empirical implications. Section 3 describes our data and how we use it to investigate the model's predictions. Section 4 presents the results of these tests and section 5 concludes.

\section{Model of Debt Maturity and Demand for Interest Rate Swaps}

In this section we derive an explicit and testable functional form of a firm's demand for interest rate swaps as well as testable implications concerning differences in the debt maturity of swap users and nonusers. Our model focuses on the demand for interest rate swaps because the overwhelming majority of firms in our sample that report using interest rate derivatives report using only swaps and/or interest rate caps. 


\subsection{Model Structure}

We pose a simple two-period model in which the firm's objective is to maximize its expected end-of-second-period cash flow while minimizing the variance. The assumption that firms sacrifice expected profits in return for lower cash flow variation is consistent with Froot, Scharfstein, and Stein (1993), who demonstrate that hedging demand can arise from the existence of a premium on external funds. Nonetheless, for practical purposes, one could invoke almost any theoretical foundation under which firms desire to minimize the volatility of some variable related to earnings, such as taxable income, to minimize taxes (Smith and Stulz, 1985), or accounting earnings, to improve signals of management quality (Demarzo and Duffie, 1995). A closely related view is that firms desire to minimize fluctuations in firm value in order to reduce the probability of costly bankruptcy (Smith and Stulz, 1985) or underinvestment (Smithson, Smith, and Wilford, 1995).

Our model has three dates, $\{t=0,1,2\}$. At $t=0$, firm $i$ chooses how much short-term debt, $F_{i}$, and long-term debt, $D_{i}-F_{i}$, to issue in order to finance a project that pays off at $t=2$. Project size, $A_{i}$, and the total amount of debt raised, $D_{i}$, are exogenous. ${ }^{6}$ At $t=0$, the firm also chooses its notional pay-fixed swap position, $S_{i}$. Short-term debt is refinanced at $t=1$, and all cash flows--including payments under the swap agreement--occur at $t=2$.

There are two primitive sources of risk in the model. The first is the risk-free rate at $t=1$; variations in the risk-free rate affect project returns, interest expense on short-term debt, and swap payments. The second type of primitive risk is a firm-specific credit premium shock at $t=1$, which also affects refinancing costs. ${ }^{7}$

\subsubsection{Risk-free rates}

For simplicity, we assume that the (gross) short-term risk-free rate at $t=0$ is equal to unity. The short-term risk-free rate at $t=1$--which is unknown at $t=0$--is denoted by $r_{1}$, and

${ }^{6} D_{i}$ represents the external funds required by the firm; thus one can think of the firm as having internal funds equal to $A_{i}-D_{i}$.

${ }^{7} \mathrm{~A}$ third source of risk--the idiosyncratic component of project returns--plays no direct role in our theoretical analysis, since neither the firm's debt maturity or swap position can be used to alter the firm's exposure to this source. 
its variance by $\sigma_{r}^{2}$. The forward rate at $t=0$ is denoted by $r_{f w d \cdot}{ }^{8}$

There is ample evidence that firms, in determining their debt maturity structure and derivatives positions, are influenced by their views about future interest rates. ${ }^{9}$ Thus, in our model, we permit individual firms to have expectations about $r_{1}$ that differ from the forward rate. We denote firm i's expectation of $r_{1}$ at $t=0$ by $E_{i}\left(r_{1}\right)$, and the difference between firm $i$ 's expectation and the forward rate, or the firm's "view", by:

$$
v_{i}=E_{i}\left(r_{1}\right)-r_{f w d}
$$

\subsubsection{Interest Rate Swaps}

The notional value of pay-fixed swaps, chosen at $\mathrm{t}=0$, is denoted by $S_{i}\left(-\infty \leq S_{i} \leq \infty\right)$, where $S_{i}<0$ corresponds to pay-floating swaps. Under a swap agreement, a firm receives the difference between the spot rate at $t=1$ and the forward rate at $t=0$ or $S_{i}\left(r_{1}-r_{f w d}\right)$. Although the payoff on the swap is revealed at $t=1$, for simplicity we assume that payments are made at $t=2$. Given our assumptions regarding the firm's expectations about the risk-free rate at $t=0$, firm $i^{\prime} s$ expected profit per unit of pay-fixed swaps is $v_{i}$.

We also assume that there are fixed costs to using swaps, denoted by $c$. As noted above, the presence of fixed costs is suggested by the strong relationship that we and others observe between firm size and derivative use.

\subsubsection{Debt}

The firm chooses short-term debt, $F_{i}$, and long-term debt, $D_{i}-F_{i}$, at $t=0$. Short-term debt is refinanced at $t=1$ following the realization of the new short-term risk-free rate, $r_{l}$, and a firm-specific credit premium shock, $\varepsilon_{i}$, where $E\left(\varepsilon_{i}\right)=0, \operatorname{Var}\left(\varepsilon_{i}\right)=\sigma_{\varepsilon, i}^{2}$. Principal and

${ }^{8}$ The forward rate is derived from short- and long-term rates in the usual way. Thus, the longterm risk-free rate in our model is $\left(r_{f w d}\right)^{1 / 2}$. In the analysis below, it is notationally simpler to use the forward rather than the long-term rate.

${ }^{9}$ Bodnar et. al (1995) report that 43 percent of firms use derivatives to "take a view" on the direction of financial prices, though only 9 percent do so frequently. However, several case studies of interest rate risk management suggest that interest rate views play a major role in determining a firm's derivatives position (see Tufano 1993, 1994, and Smithson, Smith, and Wilford, 1995, pp.271-272). 
interest on both short-term and long-term debt are repaid at $t=2$. The firm is assumed to owe $F_{i}\left(r_{1}+p_{i}+\varepsilon_{i}\right)$ on its short-term debt and $\left(D_{i}-F_{i}\right)\left(r_{f w d}+p_{i}+T_{i}\right)$ on its long-term debt, where $p_{i}+\varepsilon_{i}$ and $p_{i}+T_{i}$ are the credit premia on the firm's short-term and long-term debt, respectively.

We have taken some liberties in modeling the credit premia. Because they are modeled as payments at $t=2$, they appear to represent yield spreads or promised payments on the firm's debt. However, what we really have in mind is that $p_{i}$ and $T_{i}$, which are nonstochastic, represent a firm's expected borrowing costs over and above the risk-free rate, inclusive of all agency and asymmetric information costs. Thus, they include the expected level of bankruptcy costs, underinvestment costs, risk-shifting costs, state-verification costs, and the costs of being pooled with lower-quality types---all the costs that a firm normally bears as the result of using debt financing. For short-term debt, we assume that the expected costs of such frictions are $p_{i}>0$, whereas for long-term debt, the expected costs are $p_{i}+T_{\dot{v}}$ where $T_{i}$ can be positive or negative (though the firm uses no short-term debt if it is negative, as shown below).

By contrast, $\varepsilon_{i}$ is intended to represent the uncertainty with regard to both the cost and availability of short-term debt. In particular, it is intended to capture the fact that as new information arrives about the firm, short-term debt is repriced to reflect this information, which leads to volatility in the firm's cash flow, and in extreme cases, to the cutting off of credit altogether.

This specification of debt financing costs captures the idea that, in general, the expected costs of long-term debt tend to be greater than those of short-term debt but that using short-term debt leads to greater variation in credit costs. In the mean-variance framework used in this paper, it is a convenient way of parameterizing the relative advantages (and disadvantages) of short- and long-term debt without modelling the underlying frictions (i.e. the underlying information asymmetry and agency problems). However, the general empirical implications drawn below do not depend upon this parameterization. ${ }^{10}$

\footnotetext{
${ }^{10}$ Indeed, in our empirical work, we do not attempt to estimate the credit cost parameters $p_{i}$, $T_{i}$, and $\sigma_{\varepsilon, i}{ }^{2}$. To test the relevant implications of our model, we need only estimate reduced form debt
} 


\subsubsection{Technology}

The project's payoff at $t=2$, or its operating return, is given by

$$
\operatorname{EBITD}_{i} / A_{i}=a_{i}+\beta_{i} r_{1}+e_{i}
$$

where $a_{i}$ is a constant, $\beta_{i}$ measures the sensitivity of project return, scaled by project size, to the risk-free rate, and $e_{i}$ is the random component of project returns that is uncorrelated with the risk-free rate. A variation on this specification closer in spirit to the framework of Froot, Scharfstein, and Stein (1993) would use operating earnings net of optimal investment, or $\left(E B I T D_{i}-I_{i}^{*}\right) / A_{i}$ on the left-hand side of (2). This variation yields analogous expressions for optimum behavior, and is given further consideration in the discussion of empirical specifications.

\subsection{The Firm's Optimization Problem}

We are now ready to state the firm's optimization problem and its solution. We assume that the firm chooses its swap position, $S$, and the amount of short-term debt, $F$, in order to maximize expected cash flow (scaled by assets) subject to a constraint on the variance of (scaled) cash flow:

$$
\operatorname{Max} \text { w.r.t. } S_{i}, F_{i} \quad E_{i}\left(C F_{i} / A_{i}\right)-\lambda_{i} / 2 \operatorname{Var}\left(C F_{i} / A_{i}\right)
$$

The penalty on variance, $\lambda_{i}$, which can vary across firms, serves as a gauge of the relative importance of expected cash flow and the variance of cash flow. Cash flow at $t=2$ is just the sum of project returns and income on the swap (which can be negative), minus the cost of using swaps and repayments of short-term and long-term debt. Combining expressions for these terms, we have:

maturity regressions on observable factors such as firm size, market-to-book value of assets, and so forth. Thus, the specification of credit costs in the theoretical model is just a useful modelling device. 


$$
C F_{i}=E B I T D_{i}+S_{i}\left(r_{1}-r_{f w d}\right)-c-F_{i}\left(r_{1}+p_{i}+\varepsilon_{i}\right)-\left(D_{i}-F_{i}\right)\left(r_{f w d}+p_{i}+T_{i}\right)
$$

From (1), (2), and (3), the two components of the objective function are:

$$
\begin{aligned}
& E_{i}\left(C F_{i} / A_{i}\right)=a_{i}+\beta_{i} E_{i}\left(r_{l}\right)-\left[c+D_{i}\left(r_{f w d}+p_{i}+T_{i}\right)-\left(S_{i}-F_{i}\right) v_{i}-F_{i} T_{i}\right] / A_{i} \\
& \operatorname{Var}\left(C F_{i} / A_{i}\right)=\sigma_{e, i}^{2}+\left[\beta_{i}+\left(S_{i}-F_{i}\right) / A_{i}\right]^{2} \sigma_{r}^{2}+\left(F_{i} / A_{i}\right)^{2} \sigma_{\varepsilon, i}^{2}
\end{aligned}
$$

and the first-order conditions are:

$$
\begin{aligned}
& \text { w.r.t. } S_{i} \Rightarrow \quad v_{i}-\lambda_{i}\left[\beta_{i}+\left(S_{i}-F_{i}\right) / A_{i}\right] \sigma_{r}^{2}=0 \\
& \text { w.r.t. } F_{i} \Rightarrow \quad-v_{i}+\lambda_{i}\left[\beta_{i}+\left(S_{i}-F_{i}\right) / A_{i}\right] \sigma_{r}^{2}+T_{i}-\lambda_{i}\left(F_{i} / A_{i}\right) \sigma_{\epsilon, i}^{2}=0
\end{aligned}
$$

Defining $s_{i}$ and $f_{i}$ to be $S_{i} / A_{i}$ and $F_{i} / A_{\dot{p}}$ respectively, and observing that, from (6), the first two terms of (7) sum to zero, we can write the optimality conditions as:

$$
\begin{aligned}
& S_{i}^{*} / A_{i} \equiv s_{i}^{*}=f_{i}^{*}-\beta_{i}+v_{i} / \lambda_{i} \sigma_{r}^{2} \\
& F_{i}^{*} / A_{i} \equiv f_{i}^{*}=T_{i} / \lambda_{i} \sigma_{\varepsilon, i}^{2}
\end{aligned}
$$

The optimality conditions have a recursive structure. From (9), the optimal quantity of shortterm debt depends only on "credit factors": it is positively related to the slope of the term structure of the credit risk premium, $T_{i}$, and negatively related to the volatility of the shortterm credit premium, $\sigma_{\varepsilon, i}{ }^{2}$, and the penalty on cash flow volatility, $\lambda_{i}$. However, it is independent of the firm's swap position, $s$, and of "interest rate factors" $v_{i}$ and $\sigma_{r}{ }^{2}$. The optimal quantity of short-term debt, in turn, directly affects the firm's optimal swap position, as shown by (8).

The recursive structure of the solution is a direct result of our assumptions that (i) the 
derivative instrument--swaps--and the underlying exposure--interest rate risk--are perfectly correlated, and (ii) there are no variable swap costs. These assumptions imply that it is both possible and costless for a firm to obtain precisely its desired interest rate exposure using swaps, and hence, that the interest rate exposure implied by its debt maturity has no effect on the value of the firm's objective function.

Equation (8) characterizes a firm's swap position as the sum of a hedging and a speculative component. The hedging component, $f_{i}^{*}-\beta_{i}$, is the swap position that fully hedges the firm against fluctuations in interest rates. The speculative component is a function of the firm's view about interest rates. Firms that expect short-term interest rates to exceed the market forward rate $\left(v_{i}>0\right)$ will take a larger position in pay-fixed swaps, relative to the fully hedged position, while firms that expect interest rates to be less than the market forward rate $\left(v_{i}<0\right)$ will take a smaller position. The weight placed on the firm's view is greater, the smaller is the variance of interest rates, $\sigma_{r}{ }^{2}$, or the penalty on cash flow variation, $\lambda_{i}{ }^{11}$

Using data on both the notional amount and direction of firm swap positions, our first set of empirical tests involves testing (8). That is, we estimate:

$$
s_{i}=h_{0}+h_{1} f_{i}+h_{2} b_{i}+u_{i}
$$

where $s_{i}$ is the ratio of the notional value of pay-fixed swaps to assets, $f_{i}$ is the ratio of shortterm debt to assets, $b_{i}$ is (an estimate of) the interest rate sensitivity of operating earnings, and $u_{i}$ is an error term that, in part, reflects a firm's interest rate view. Our model predicts that the hedge ratios, $h_{l}$ and $h_{2}$, are equal to +1 and -1 , respectively.

\subsection{Optimal Debt Maturity of Firms that Do Not Use Swaps}

Despite the potential benefits of using derivatives, many firms don't use them. All recent empirical studies, including our own, document a very strong relationship between firm

\footnotetext{
${ }^{11}$ Another way to think about (8) is that $s_{i}-f_{i}+\beta_{i}$ measures the actual linear relationship between the firm's cash flow (over assets) and interest rates, while $v_{i} / \lambda_{i} \sigma_{r}^{2}$ measures the desired linear relationship; hence, the firm's swap position is the value of $s$ that equates the actual with the desired linear relationship.
} 
size and the use of derivatives, which suggests that there exist fixed costs of some sort to using derivatives. In our model, firms will not use swaps if the utility gain from doing so is less than $c$. We identify such firms as being "constrained" by transactions costs.

Firms that do not use swaps maximize the identical objective function as before using only the choice of debt maturity, $F_{i}$. In this "constrained" case, the first-order condition for the choice of $F_{i}$ is again given by (7) (with $S_{i}$ set equal to zero), and the firm's optimal choice of $f_{i}=F_{i} / A_{\mathrm{i}}$ satisfies:

$$
f_{i}^{* c}=\left(T_{i}-v_{i}+\lambda_{i} \beta_{i} \sigma_{r}^{2}\right) / \lambda_{i}\left(\sigma_{\varepsilon, i}^{2}+\sigma_{r}^{2}\right)
$$

Of primary interest is how the debt maturity of nonusers compares with that of swap users. Letting $f_{i}^{* u}$ denote the optimal choice of $f_{i}$ for swap users given in (9), we can express a nonuser's optimal debt maturity as:

$$
f_{i}^{*_{c}}=\theta_{i} f_{i}{ }^{*_{u}}+\left(1-\theta_{i}\right)\left(\beta_{i}-v_{i} / \lambda_{i} \sigma_{r}^{2}\right)
$$

where $\theta_{i}=\sigma_{\varepsilon, i}^{2} /\left(\sigma_{\varepsilon, i}^{2}+\sigma_{r}^{2}\right)$.

From (11), a nonuser's choice of debt depends upon the same factors that influence a swap users choice of debt (the first term), but also depends upon the interest sensitivity of its cash flow and its view on interest rates (the second term). From the expression for $\theta_{\dot{v}}$ the weight given to "credit factors" and "interest rate factors" depends upon the relative amount of variation in the credit premium, $\sigma_{\varepsilon, i}{ }^{2}$, and the risk free rate, $\sigma_{\mathrm{r}}{ }^{2}$.

Equations (9) and (10) (or (11)) form the basis for our second set of tests, which relate to difference in the debt maturities of users and nonusers. This difference is most easily understood in the case where a firm has no economic exposure $\left(\beta_{i}=0\right)$ and a neutral view about interest rates $\left(v_{i}=0\right)$. For this case, our model offers two clear predictions. First, controlling for firm characteristics $T_{i}, \lambda_{i}$ and $\sigma_{\varepsilon, i}^{2}$, firms that do not use swaps should use less short-term debt. This can be seen from the fact that with $\beta_{i}=0$ and $v_{i}=0$, (9) and (10) have the same numerator but (10) has $\sigma_{r}^{2}$ in the denominator. (Alternatively, it can be seen 
from (11) and the fact that $\theta_{i}<1$.) Intuitively, all else the same, nonusers are more reluctant to use short-term debt since they can not offset the resulting exposure to interest rate risk. Second, and relatedly, the debt structure choice of swap users is more sensitive to their characteristics; that is, the partial derivatives of $f^{*}$ with respect to $T_{i}, \lambda_{i}$, and $\sigma_{\varepsilon, i}{ }^{2}$ are larger, in absolute value, for users than for nonusers. Again, nonuser sensitivity to such factors is damped by their concern with interest rate risk. ${ }^{12}$

\subsection{Testing for Differences in Debt Maturity}

We test these predictions using linearized versions of (9) and (10), whereby a measure of debt maturity is regressed on observable factors found to have predictive value for debt structure in previous studies and (in the case of (10)) on an estimate of a firm's economic exposure to interest rate risk, $\beta_{i}$. The general linear specification is:

$$
f_{i}=g^{\prime} z_{i}+\gamma b_{i}+w_{i}
$$

where the vector $z_{i}$ includes an intercept and the financial characteristics that influence the relative costs of funding with short-term debt, $b_{i}$ is an estimate of the interest rate sensitivity of operating earnings (as in $\left(8^{\prime}\right)$ ), and $w_{i}$ is an error term that may reflect, in part, a firm's view on interest rates.

Using (13), we perform two different tests. First, we estimate (13) over the entire sample and include a dummy variable that equals one for swap users. Our model predicts that the coefficient on the dummy variable will be positive. ${ }^{13}$ Second, we investigate whether

\footnotetext{
${ }^{12}$ For the case where $\beta_{i} \neq 0$ and $v_{i} \neq 0$, the predictions of our model are complicated by the fact that $f^{* c}$ is a nonlinear function of these parameters and of $T_{i}, \lambda_{i}$, and $\sigma_{\varepsilon, i}{ }^{2}$. However, the results of debt maturity regressions (presented in section 4) suggest that nonusers do not use debt maturity to hedge their economic exposure to interest rate risk. Thus, debt maturity appears to be chosen "as if" $\beta_{i}=0$, as assumed above. Firms' interest rate views are unobservable and are impounded in the error term of these regressions. Assuming that interest rate views average to zero across firms and are independent of other factors that affect a firm's choice of debt maturity, the preceding predictions on the relationship between the debt maturity of users and nonusers should hold.

${ }^{13} \mathrm{We}$ interpret a positive coefficient on the dummy variable to measure the increase in shortterm debt that arises as a result of a firm's using swaps---that is, the difference between $f^{* u}$ and $f^{* c}$.
} 
the debt maturity choice of swap users is more sensitive to firm-specific characteristics. We test this by estimating (13) separately for users and nonusers and comparing coefficient estimates across the regressions.

\subsection{The Underlying Determinants of Firm Swap Positions}

Our final set of empirical tests focuses on the relationship between a firm's swap position, $s_{i}$, and the determinants of its debt maturity, $z_{i}$. According to our model, these firmspecific characteristics are the underlying determinants of the firm's swap position through their influence on the firm's choice of debt maturity. Thus, we re-estimate equation (8'), but instead of including $f_{i}$ as a regressor, we include the determinants of $f_{i}$ given in (13). That is, we estimate:

$$
s_{i}=g_{s}^{\prime} z_{i}+h_{2} b_{i}+u_{i}
$$

Estimating (14) provides a robustness check on our model. More importantly, as discussed in the next section, the underlying determinants of a firm's debt structure may explain firm swap positions better than debt structure itself given the potential problems of measuring the latter.

\section{Data Sources and Empirical Methodology}

To investigate the various predictions described in section 2, we gather information on over 4000 publicly traded nonfinancial corporations using Compact Disclosure and

However, an alternative interpretation is also possible: a positive coefficient could simply indicate that firms that use more short-term debt are more likely to use swaps. In econometric terms, the coefficient on the use dummy may be subject to simultaneity bias.

The extent and even direction of the simultaneity bias is ambiguous because the relationship between short-term debt and the probability of swap use is ambiguous. Recall that in our model a firm uses swaps if the utility gain from doing so exceeds the cost. It can be shown that, in response to an increase in the optimal quantity of short-term debt $\left(f^{*}\right)$, the probability of using pay-fixed swaps increases, while the probability of using pay-floating swaps decreases. Simultaneity bias is positive only if the former exceeds the latter. In at least one simple case--when firm interest rate views $\left(v_{i}{ }^{\prime} s\right)$ are uniformly distributed--these changes just offset each other and the simultaneity bias is zero. 
Compustat. The universe of firms in our sample includes firms that satisfy the following four conditions: (i) the June 1995 Compact Disclosure disk contains the text of a recent (postNovember 1993) 10-K filing; (ii) there is (matching) annual data from Compustat for the same fiscal year; (iii) the firm has at least $\$ 1$ million in assets that year; and (iv) the firm is nonfinancial in nature, i.e., its primary SIC is not in the 6000s, and the firm does not have a major finance company subsidiary.

\subsection{Extraction of Information on Derivative Use}

To gather information on a firm's use of interest rate derivatives, we begin by searching the text fields of each firm's latest 10-K and annual report using Compact Disclosure. We search for keywords including DERIVATIVES, DERIVATIVE, HEDGE, HEDGING, HEDGED, HEDGES, FUTURES, SWAPS, OR SWAP. Where we obtain a keyword match, we scrutinize the available information to verify that the firm used interest rate derivatives as of their fiscal year-end.

As reported in table 1, slightly more than 9 percent of our sample, or 384 out of 4209 firms reported using interest rate derivatives. The positive correlation between firm size and derivative use, so apparent in earlier studies, is evident in our data as well. Slightly more than half of the largest firms in our sample--firms with over $\$ 2.5$ billion in assets--report using interest rate derivatives. This percentage drops steadily to only 1 percent for the smallest firms, those with under $\$ 100$ million in assets. These findings are somewhat surprising given the recent vintage of our dataset. Some analysts have conjectured that, over time, derivative use will spread to smaller firms (e.g. Smithson, Smith, and Wilford, 1995); our data suggests that, as of year-end 1994, this diffusion had not occurred to any great extent.

Table 1 also reports how derivative use varies among firms with different senior bond ratings. Interestingly, the largest number of derivatives users in our sample have no senior bond rating, though the percentage of firms using derivatives is monotonically related to 
ratings and is highest for firms rated $\mathrm{A}$ and above. ${ }^{14}$

For firms that reported using interest rate derivatives, we obtain information on the types of derivatives used (i.e. swaps, caps, collars, futures, options, and forward contracts), and the direction and notional amount of each type, when this information is available. As shown in table 2a, the overwhelming majority of derivative users reported using either swaps or caps (and in some cases, both). Fewer than 5 percent--15 out of 384--reported using futures, forward, or option contracts. Of the 350 swaps users, 260 report the direction of their swaps, and 233 report the direction and the notional amount of their swaps. All 57 cap users reported being long caps, and 46 cap users reported the notional value of their caps.

We construct two different scalar measures of a firm's swap position, $s$. The first measure, Swapl, uses only data on swaps. As in our model, Swapl is equal to the notional value of pay-fixed swaps, divided by assets, with pay-floating swaps assigned a negative value. Swapl is constructed for only those firms that report the direction and notional value of their swaps. For firms with swaps in both directions, we require data on the notional amount in each direction and use these to construct a net notional position, equal to pay-fixed notional minus pay-floating notional. ${ }^{15}$

The second measure, Swap2, uses data on caps as well. Caps are treated as pay-fixed swaps and notional cap amounts are added to the numerator of Swap $1 .{ }^{16}$ Of course, the delta of out-of-the-money caps can be considerably less than 1, and we make no attempt to compute the delta, as the necessary information is generally not available. Thus, for firms using caps, Swap1 represents a lower bound on $s$, while Swap2 represents an upper bound.

\footnotetext{
${ }^{14}$ As discussed below, we obtain ratings information for both publicly-traded and privatelyplaced bonds. Thus, unrated firms include only firms that have neither public or private bonds outstanding.

${ }^{15}$ By collapsing pay-fixed and pay-floating swaps into a single position, we oversimplify the nature of a firm's hedge; see below.

${ }^{16}$ Swap2 is also defined for firms that use only caps; for these firms, Swap2 is equal to cap notional divided by assets. In no case do we define Swapl or Swap2 when the direction or notional amount of a firm's swap position is ambiguous. For example, if a firm provides insufficient information for us to construct Swapl but reports the notional value of its caps, we do not define Swap2 for this firm, because the firm's overall position is ambiguous.
} 
Table $2 \mathrm{~b}$ provides descriptive statistics on Swapl and Swap2. The distributions of the two measures are very similar. Each has a positive median, consistent with the greater number of firms using only pay-fixed swaps. Half of the sample has a net notional Swapl position distributed between -.05 and .08 ; for Swap2 this range is -.03 to .09 . Both distributions are long-tailed, with minimums of -.57 and maximums of 1.05 and 1.34.

\subsection{Definition and Construction of Short-Term Debt Variable}

Two issues arise in deciding upon the measure of short-term debt to use in testing the predictions of our model. The first relates to the repricing frequency of the risk-free component of the interest rate on the debt included in $f$. In principle, it should roughly correspond to the frequency of repricing on the floating side of the interest rate swap. From this perspective, a reasonable measure of $f$ is the sum of debt maturing within a year and floating-rate long-term debt.

This definition of $f$, along with our definitions of Swap1 and Swap2, embodies an overly simplistic view of how swaps are used to hedge interest rate risk. In particular, it abstracts from how swaps can be used to hedge interest rate changes on debt that is repriced less frequently than within a year. However, to calculate the extent to which firms hedge longer-term interest rate exposure would require maturity information about individual swap contracts that is generally not available to us. Accordingly, our measure of $f$ also excludes debt repriced less frequently than within a year. ${ }^{17}$

The second issue that we must consider in defining $f$ is whether our definition corresponds to "short-term debt" from the perspective of theories of optimal debt maturity.

${ }^{17}$ Consider, for example, a firm with two swaps: a ten-year pay-fixed (receive-floating) swap with a notional value of $\$ 100$ million and a two-year pay-floating (receive-fixed) swap with a notional value of $\$ 50$ million. We treat this as a single $\$ 50$ million pay-fixed swap. In reality, the firm's position is more complex: the firm has, in effect, swapped $\$ 50$ million of floating rates and $\$ 50$ million of two-year rates into ten-year rates. This strategy could be used to hedge $\$ 50$ million of floating-rate debt and $\$ 50$ million of two-year debt over a ten-year horizon. If such a firm actually had $\$ 50$ million of floating-rate debt and $\$ 50$ million of two-year debt, only the former would be included in our definition of $f$. Note that we would still arrive at the (correct) conclusion that the firm had perfectly hedged its floating-rate debt, but we would have nothing to say about whether or not the firm had hedged its two-year debt. 
These theories focus on the frequency at which the credit-premium component of borrowing rates are repriced. Previous empirical studies of debt maturity employ various measures: Titman and Wessels (1988) use debt maturing within one year while Barclay and Smith (1995) use debt maturing within three years. Stohs and Mauer (1996) construct a weighted average maturity of a firm's entire liability portfolio, not just its debt. A shortcoming of all of these measures is that they do not distinguish between stated and effective maturities. As Barclay and Smith (1995) note, call provisions, prepayment options, and affirmative covenants can result in effective maturities that are significantly less than stated maturities.

The sum of debt maturing within a year and floating-rate long-term debt--which is an appropriate measure of $f$ from the standpoint of measuring a firm's exposure to interest rate risk--is also a useful measure of short-term debt from the perspective of theories of optimal debt maturity. This is because the vast majority of floating-rate long-term debt consists of bank loans. Bank loans, although nominally long-term, leave both the firm and the bank substantial flexibility to terminate or, equivalently, renegotiate key terms before the loan's maturity date. In particular, borrowers typically can prepay such loans anytime without penalty, while banks typically can refuse to extend additional credit if there are material adverse changes in the borrower's financial condition. Banks also can reset the credit premium as a condition for renegotiating restrictive loan covenants. For these reasons, the credit premium on bank loans, while nominally fixed, is effectively floating, and hence, floating-rate bank loans share many of the characteristics of short-term debt.

Compustat is our primary source for information about a firm's debt composition. Compustat reports floating rate long-term debt--defined as any long-term debt tied to a fluctuating or floating rate--for roughly half of the firms in its database. Moody's Industrial Manual was used to verify, and in several cases, correct errors in the Compustat debt composition of swap users. Using Moody's, we verify that the majority of floating-rate longterm debt, as reported in Compustat, consists of bank loans, and find that the balance, to our surprise, consists largely of commercial paper, which clearly is short-term debt. ${ }^{18}$

${ }^{18}$ Apparently, companies may report short-term debt, such as commercial paper, as long-term debt if the firm intends to roll over the debt and has the ability to do so. This ability can be demonstrated by the existence of committed bank "backup" lines. 


\subsection{Constructing Estimates of Operating Exposure to Interest Rates $\left(\beta_{i}\right)$}

We use Compustat to extract an annual time series on operating earnings and assets for these firms from 1982 to 1995 , or as much of this period as is available. These timeseries data are used to generate estimates of the interest-rate sensitivity of operating incometo-assets, the $b_{i}{ }^{\prime} s$ in equations (8'), (13) and (14).

In principle, estimation of the interest rate sensitivities is straightforward. The main complication is that, for some firms, this elasticity would be estimated using a relatively short time series and, thus, would contain a significant degree of error. An alternative approach, which should reduce the influence of such errors (and the approach we actually use for the results reported below) is to estimate industry-level interest rate elasticities. We estimate an

elasticity for each 3-digit industry represented in our sample using a pooled regression for all sample firms in that industry. Specifically, we estimate:

$$
\operatorname{EBITD}_{i t} /\left(A_{i t} / 2+A_{i, t-1} / 2\right)=a_{j}+\beta_{j} r_{t}+e_{i t}
$$

where, in our primary specification, $E B I T D_{i t}$ denotes operating earnings before interest and depreciation for firm $i$ in year $t, A_{i t}$ denotes assets of firm $i$ at the end of year $t, r_{t}$ is the average 3-month treasury bill rate during year $t$, and $j$ indicates firm $i$ 's industry as measured by its primary 3-digit SIC code.

\subsection{Specification of debt-maturity regressions.}

Two issues arise in determining an appropriate specification of the debt-maturity regression. The first concerns the appropriate choice of regressors. The second is whether the behavioral variable that these regressors help explain is more accurately modeled as the ratio of short-term debt to total assets or short-term debt to total debt.

\subsubsection{Choice of regressors}

To estimate a debt maturity regression like (13), we use cross-sectional explanatory variables $\left(z_{i}^{\prime} s\right)$ found to have predictive value in previous debt maturity studies (e.g. Barclay and Smith, 1995, Guedes and Opler, 1995, and Stohs and Mauer, 1996). These include: (i) 
size, as measured by $\log$ (sales); (ii) the market-to-book ratio of assets; (iii) asset maturity, as measured by the ratio of inventories and receivables to total assets; and (iv) senior debt ratings. ${ }^{19}$ The justifications for including such variables is spelled out in detail in the studies cited above and are only summarized here.

One of the most widely-invoked rationales for issuing short-term, rather than longterm, debt is that it minimizes potential agency costs by giving lenders greater ability to respond to management performance or economic conditions affecting the firm's prospects (Barnea, Haugen, and Senbet, 1980). Smaller less established firms likely pose greater risk of agency problems from the lender's perspective, since such firms likely face a more uncertain environment and because management may be more able and willing to collude with owners against the interest of lenders (Smith and Warner, 1979). Firm size is thus intended as a proxy for agency costs, and smaller firms are predicted to use more short-term debt. In addition, smaller firms are more likely to use short-term debt to the extent that there are scale economies in long-term debt (i.e. fixed costs of issuing publicly-traded and privately-placed bonds; see Barclay and Smith, 1995).

The ratio of market-to-book value is conventionally considered to be a measure of the extent to which a firm's value is dependent on the optimal exploitation of risky growth opportunities. The presence of substantial growth opportunities can give rise to agency conflicts between long-term creditors and shareholders: in particular, firms may either underinvest (Myers, 1977) or select inefficient but risky projects (Barnea, Haugen, and Senbet, 1980). This agency cost perspective suggests that growth-option-oriented firms face greater costs of issuing long-term debt, and thus, avoid doing so (Barclay and Smith, 1995). On the other hand, as pointed out by Guedes and Opler (1995), firms that face risky growth opportunities may also face larger costs in the event of a refinancing crisis (Diamond, 1991 and Sharpe, 1991); consequently, they may be more inclined to issue long-term debt despite the steeper price. Thus, the predicted relationship between long-term debt and market-to-book

\footnotetext{
${ }^{19} \mathrm{We}$ also considered a number of other variables, such as the ratio of R\&D to assets, earnings and dividend yields, alternative measures of asset maturity, and earnings surprises. However, to keep the debt maturity specifications relatively simple, we excluded variables that demonstrated little or no explanatory power.
} 
value is ambiguous.

Underinvestment and risk-shifting are most likely to arise when the maturity of a firm's debt exceeds the maturity of its assets (Myers, 1977), while refinancing problems and inefficient liquidation are most likely to arise when the maturity of a firm's debt is less than the maturity of its assets; consequently, maturity matching can reduce the severity of each of these agency conflicts (Stohs and Mauer, 1996). Maturity matching implies that firms whose assets are largely inventories and receivables should tend to use more short-term debt.

Finally, debt maturity may be systematically related to a firm's credit rating. As argued by Diamond (1991), low-rated firms rely heavily on short-term financing because they have no choice--long-term financing either is not available or is prohibitively expensive-while high-rated firms rely heavily on short-term financing when they have private information about impending improvements in their credit rating. Intermediate-rated firms, by contrast, prefer to finance with long-term debt, despite its relatively high cost, owing to the rollover risk of short-term debt.

We include dummy variables for broad bond rating categories as a test of Diamond's (1991) hypothesis. Ratings of publicly-traded debt are obtained from Compustat, Moody's Industrial Manual, and S\&P's Bond Guide. A potentially important innovation in our ratings data is that we also include ratings of private placements issued by the Securities Valuation Office of the National Association of Insurance Commissioners. Thus, our ratings variables refer to the rating of either a firm's publicly-traded or privately-placed debt, and unrated firms include only those without either rating. By including private placement ratings, the standard assumption that unrated firms correspond to Diamond's (1991) riskiest or lowest-rated firms is more likely to be satisfied. ${ }^{20}$

\subsubsection{Choice of debt maturity variable}

Debt maturity equation (13) assumes that the relevant firm decision variable is the ratio of short-term debt to total assets. In their empirical study, Titman and Wessels (1988) model the firm's debt maturity decision in this way. However, other empirical studies (e.g.

\footnotetext{
${ }^{20}$ Other debt maturity studies use only public bond ratings; consequently, these studies group firms that issue highly-rated private placements with firms that have no public or private bonds outstanding. In reality, the latter are probably riskier than the former.
} 
Barclay and Smith, 1995 and Stohs and Mauer, 1996) assume that the relevant decision variable is debt composition, or the ratio of short-term debt to total debt. To allow our results to be more easily compared to these studies, we estimate a variant of (13) in which the vector of firm-specific characteristics, $z_{i}$, is interacted with firm leverage, $D_{i} / A_{i}$ :

$$
f_{i} \equiv F_{i} / A_{i}=g^{\prime} z_{i}\left(D_{i} / A_{i}\right)+\gamma b_{i}+w_{i}
$$

One can view (13') as a regression explaining $F / A$; alternatively, since $F_{i} / A_{i}=\left(F_{i} / D_{i}\right)\left(D_{i} / A_{i}\right)$, (13') could be thought of as a weighted least squares regression of $F_{i} / D_{i}$ on $\left\{z_{i}\right\}$ with $D_{i} / A_{i}$ used as regression weights. If $F_{i} / D_{i}$ is the appropriate behavioral variable to be explained by firm financial characteristics $\left(z_{i}\right)$, then (13') ought to outperform (13). Indeed, we find this to be the case. $^{21}$

\section{Empirical Results}

In general, it was necessary for us to know both the direction and the size of a firm's swap position, the amount of the firm's debt maturing within a year (i.e. in current liabilities), and the amount of its floating-rate long term debt. As was shown in table 2, swap data requirements leave us with a sample of 233 swap users; in addition, we know the notional amounts of interest rate caps for 19 firms that do not report using swaps. The swap/cap user sample is cut down by about half by our inability to get complete information on floating-rate long-term debt for many firms.

Table 3 provides information on the distribution of the variables for the 130-firm sample used to estimate equation (8'). The distribution of Swapl and Swap2, shown in rows

\footnotetext{
${ }^{21}$ We recognize that leverage, $D_{i} / A_{i}$--which appears on the right-hand side of (13') and which we treat as pre-determined--is also, in principle, endogenous. Of course, we are, in effect, only using leverage as a weight (in an $F_{i} / D_{i}$ regression), and not as a regressor. However, as a robustness check, we also estimate an unweighted regression of $F_{i} / D_{i}$ on $z_{i}$. As shown in section 4 , this regression yields results that are very close to those obtained from estimating (13'). Note that regardless of the appropriate specification, the fundamental logic of our model remains the same: swap users choose the quantity of short-term debt that minimizes credit costs, while nonusers choose less than the credit-costminimizing amount owing to interest rate risk.
} 
1 and 2 , is similar to that for the broader sample shown in table $2 \mathrm{~b}$. The third row reports the sample distribution of our short-term debt measure, $f$. While short-term debt is less than 0.15 for half the firms, this variable has a right-skewed distribution. Row 4 shows the distribution of interest rate elasticities of firm operating earnings before interest, estimated at the industry level. The median value of $\beta$ is positive, implying that most firms tend to receive more operating cash flow when interest rates are high. It is instructive to note that a value of -1 corresponds to the same level of interest rate risk exposure from operating income as would be generated by a short-term debt-to-asset ratio of 1 . As table 3 indicates, three-quarters of our sample have a short-term debt-to-asset ratio of less than 0.25 . Thus, our estimates of $\beta$ imply that the sensitivity of operating income to fluctuations in interest rates for many firms is a source of much greater cash flow volatility than their debt obligations. ${ }^{22}$

\subsection{Swap Regression Results}

Table 4 presents our results from estimating interest rate swap regressions. In each specification, in addition to the structural variables we include a linear control for the time period--the month and year (1993 or 1994) in which the firm's balance sheet and derivative position is observed. ${ }^{23}$

The first two columns report OLS regression results for each of our two alternative measures of firms' interest rate swap positions: Swapl, which reflects only the firm's net swap position (in the pay-fixed direction), and Swap2, which also reflects interest rate caps. In

\footnotetext{
${ }^{22} \mathrm{We}$ also generated firm-level estimates of $\beta$ and found their distribution to have many more observations outside the range $(-1,1)$; for many firms, such estimates were generated with fewer than 6 observations, and had large standard errors. When these estimates were used as explanatory variables in the swap regressions, results were not robust to the precise method used to estimate them, such as the choice of including or excluding a time trend. For this reason, we focus on results based on industry-level elasticities.

${ }^{23}$ The linear control for time has a positive regression coefficient which is significant at the 1 percent level in the Swap2 specification. This variable--which has a value of 0 in December 1994 and declines by 1/12 per month as the filing date moves back in time to June 1993--controls for any time-related effects on reported swap positions. The positive coefficient on time suggests that nonfinancial firms moved toward greater pay-fixed swap positions, perhaps in response to the shift from a declining rate environment in 1993 to a rising rate environment in 1994.
} 
each case, the coefficient on $f$ is around 0.5 and is highly significant, providing strong evidence that nonfinancial firms use interest rate derivatives to hedge the interest rate risk arising from their short-term debt obligations. Such hedging accounts for approximately 20 percent of the cross-sectional variation in swap positions. ${ }^{24}$

In contrast, the small and statistically insignificant coefficients on industry $\beta$ suggest that, in general, firms do not hedge the interest rate risk engendered by the correlation of their net operating cash flow with interest rates. The robustness of this negative finding is examined in a number of ways, including estimation of $\beta$ 's using changes in cash flow on changes in interest rates, and estimation of interest rate sensitivities at the firm level. In addition, we try using $\beta$ 's estimated on cash flow net of capital expenditures, as might be suggested by Froot, Scharfstein and Stein (1993). ${ }^{25}$ Depending upon the precise methodology we use to estimate beta, its coefficient in the swap equation was sometimes significant at the 5 percent level but is not robust to the elimination of a couple highly influential observations; in no case did the coefficient exceed 0.03 in absolute value. We also consider less parametric approaches that might be less vulnerable to measurement error. For example, we use dummy variables indicating firms or industries with significantly positive betas, and another indicating firms or industries with significantly negative betas.

A potential difficulty that arises in estimating $\left(8^{\prime}\right)$ concerns the possible endogeneity of debt maturity structure, $f$. Under our assumptions, it was shown that a swap user's choice of $f$ is exogenous with respect its chosen swap position; nonetheless, it is quite plausible that in

\footnotetext{
${ }^{24}$ Note, however, that the coefficient on $f$ is significantly less than its theoretically predicted value of unity, implying that firms, on average, do not fully hedge debt-related interest rate risk. Among the possible explanations is that in addition to the fixed costs of using swaps (which in our model have no effect on $s^{*}$ ), there may also be variable swap costs, such as the costs of credit guarantees.

${ }^{25}$ Their theory shows that firms desire to smooth the difference between cash inflows and optimal investment expenditures, the latter of course being unobservable. Unfortunately, the investment literature suggests it is difficult to come up with very good instruments for optimal investment. Moreover, the theory suggests that using actual investment as an stand-in for optimal investment when estimating net cash flow betas is problematic because this stand-in is spuriously correlated with cash flow. For this reason, we do not emphasize our swap regression results based upon net cash flow betas, which, in any case, were similar to the ones reported in the tables.
} 
a more general model $f$ would be chosen simultaneously with $s .{ }^{26}$ We therefore consider, in addition to ordinary least squares estimation, the more conservative approach of estimating $\left(8^{\prime}\right)$ using instrumental variables. In this specification, the instruments for $f$ are drawn from the explanatory variables in the debt maturity regression, i.e. from the $z_{i}$ in (13'). The use of instrumental variables is also warranted on grounds that our short-term debt variable may be measured with error; in this case, using instruments eliminates the resultant downward bias in the estimated coefficient on $f$.

The results of the instrumental variables (IV) specifications are reported in the third and fourth columns. The coefficients on $f$ for both Swapl (.65) and Swap2 (.74), are somewhat larger than in the OLS regressions, bolstering our initial conclusions. Again, beta is found to have no effect on swap position.

Another potential difficulty with estimating (8') arises if firms use other hedging instruments--for example, foreign exchange derivatives--to hedge their interest rate risk. Indeed, in theory, a hedging strategy of minimizing the variance of cash flow would consist of using all available hedging instruments, with the position in each instrument determined by the multivariate regression coefficient of cash flow on that instrument (Hentschel and Smith, 1995). To account for this possibility, we use information on whether a firm has foreign exchange derivatives (gathered in our original keyword search) and estimate (8') separately for swap users that use foreign exchange derivatives and swap users that do not.

In our sample of 130 swap and cap users, 40 firms reported using foreign exchange derivatives while 90 firms did not. Using either Swapl or Swap2 as the dependent variable, the regression estimates (not shown in table) for the subsamples of foreign exchange derivative users and nonusers are virtually identical; for both specifications, the F-statistic for testing the null hypothesis of equality of the regression coefficients across the two subsamples is less than 0.5 .

As a final robustness test (not shown in table), we estimate separate regression coefficients for the two components of $f$---debt maturing within a year and floating-rate long-

\footnotetext{
${ }^{26}$ In our model, this will be the case if there are variable swap costs and the marginal cost of using swaps is a positive function of the size of the position.
} 
term debt. The regression coefficients on floating-rate long-term debt are between 0.5 and 0.6. By contrast, the regression coefficients on debt maturing within a year are around 0.2 and are insignificantly different from zero. However, because the standard errors of these latter estimates are large, we cannot reject the null hypothesis of identical coefficients on the two components of $f$ (at the 5 percent level) for either the Swap1 or Swap2 regressions.

\subsection{Debt maturity regression results}

This section reports results from estimating debt maturity regressions for swap users and nonusers. We begin by reporting results for (13') in table 5 and then report results for (13) as well as several other specifications in table 6. For the purpose of estimating debt maturity regressions, we restrict the sample to firms having at least $\$ 50$ million in assets. ${ }^{27}$ We also examine specifications with and without senior debt ratings. Specifications without ratings are considered for two reasons: first, because ratings may be highly correlated with firm size, and second, because the choice of getting a rating is, to some extent, endogenous. Consistent with (13'), all explanatory variables except for industry $\beta$ (but including the intercept) are pre-multiplied by firm leverage. ${ }^{28}$

Column 1 of table 5 reports the results of estimating (13') for the combined sample of 122 swap users and 986 nonusers. Short-term debt has the predicted negative relationship with firm size, a weak albeit positive relationship with market-to-book value (p-value=.13), and a strong positive relationship with short-term (over total) assets. Industry betas have a positive influence on the short-term debt issuance of nonusers (as predicted by eqn (10)), but the effect is very small. In this respect, our results parallel those obtained in section 4.1 for

\footnotetext{
${ }^{27}$ Subsample analysis found nonrobustness among nonusers when very small firms were included. In particular, estimated debt structure determinants looked very different for firms with assets under $\$ 50$ million. The stability of estimates is critical for our analysis because of our desire to test for differences between users' and nonusers' debt structures. Truncating the sample eliminates only 4 swap users, the smallest of which had \$24 million in assets. Although debt maturity regressions for swap users are not sensitive to the exclusion of these four firms, they are excluded for simplicity and consistency.

${ }^{28}$ Although the ordinary intercept is excluded from the regression, when included, its value is never far from zero.
} 
swap users: firms do not appear to use their debt positions to hedge (to any significant degree) their operating exposure to interest rate risk.

Of key interest is the coefficient on the swap user dummy variable. It has the predicted positive sign and is highly significant. Moreover, its magnitude appears quite large. Recall that (13') can be thought of as a (weighted least squares) regression of $F / D$ on the explanatory variables. Thus, the coefficient on the swap user dummy variable $(0.15)$ implies that, ceteris paribus, short-term debt, as a percentage of total debt, is 15 percentage points higher for swap users than for nonusers.

To determine whether the larger amount of short-term debt issued by swap users is the result of greater sensitivity to the regressors included in table 5, we estimate swap regressions separately for users and nonusers (columns 2 and 3). The intercepts of the nonuser and user regressions are nearly identical; by contrast, the coefficient on size is almost twice as large in absolute value for users (-0.05 vs. -0.09), while the coefficient on market-to-book is over four times as large (0.02 vs. 0.08). Although the regression coefficients for users are not uniformly larger in absolute value--in particular, the regression coefficient on the ratio of inventories and receivables to assets is slightly smaller--on balance, these results suggest that the short-term debt choice of swap users is more sensitive to its determinants, just as our theory predicts.

Column 4 adds senior debt ratings to the regression in column 1. The primary reason that we chose the rating categories $\mathrm{A} \&$ above, $\mathrm{BBB}$, and $\mathrm{BB} \&$ below, is that these correspond to the rating classes for private placements. As anticipated, including ratings diminishes the explanatory power of size---indeed, it knocks size out altogether. The pattern of the coefficients on the rating variables is consistent with Diamond's (1991) hypothesis: Unrated firms use significantly more short-term debt than rated firms (i.e. all the coefficients on all of the rating variables are significantly negative), while low-rated firms (BB \& below) use the least amount of short-term debt (i.e. the coefficient on the BB \& below dummy variable is most negative). Including ratings does not significantly affect the remaining coefficients: most importantly, the coefficient on the swap user dummy remains positive and highly significant.

Again, we estimate the debt maturity regression separately for nonusers and users to 
investigate the prediction that the debt maturity choice of swap users exhibits greater sensitivity to firm characteristics (columns 5 and 6). The results, if anything, suggest greater differences between swap users and nonusers than suggested by the regressions reported in columns 2 and 3. The coefficients on size, market-to-book, and asset maturity all have the predicted sign for swap users, and the coefficients are larger (in absolute value) than those estimated for nonusers (for nonusers, the coefficient on size has the wrong sign). In addition, the relationship between ratings and debt maturity predicted by Diamond (1991) appear more pronounced for swap users.

On the whole, the regressions reported in table 5 offer strong support for the predictions of our model regarding the difference in debt maturity of swap users and nonusers. Clearly, however, one might wonder how robust these results are to alternative specifications of the debt maturity equation. Therefore, in table 6 we report the results for several alternative specifications. For the sake of brevity, we report only the results of regressions estimated over the combined sample with ratings included (as in column 4 of table 5).

Column 1 reports the results of estimating (13): that is, we regress $F / A$ directly on the explanatory variables. We expect the coefficients on the explanatory variables to be smaller in magnitude than in table 5 , which they are, simply because the ratio of short-term debt to total assets is less than the ratio of short-term debt to total debt. The adjusted- $\mathrm{R}^{2}$ for this regression is only 0.08 , compared to 0.52 for the regression reported in column 4 of table 5 , which suggests that the ratio of short-term debt to total debt, rather than short-term debt to total assets, is the appropriate decision variable. Nevertheless, the coefficient on the swap user dummy is positive and highly significant. ${ }^{29}$

The regression of $F / A$ directly on firm characteristics is mispecified, in part, because we do not control for leverage. In column 2 we introduce leverage in the simplest possible way: as an additional regressor. The inclusion of leverage significantly increases the explanatory power of the regression, and brings the pattern of coefficients on the other

\footnotetext{
${ }^{29}$ The coefficient (0.1) implies that the ratio of short-term debt to assets is 10 percentage points higher for swap users than nonusers, which implies an even greater difference in short-term debt as a share of total debt (provided that debt-to-assets is less than unity).
} 
explanatory variables more in line with that observed in table 5. The coefficient on the swap user dummy is reduced by half, but the conclusion that swap users issue more short-term debt is unaffected.

In column 3 we report the results of estimating an unweighted regression of $F / D$ on firm characteristics. The coefficients of this regression should correspond closely to those in column 4 of table 5 unless using leverage as weights strongly influences our results; indeed, the coefficients are very similar. (Note that the adjusted- $\mathrm{R}^{2} \mathrm{~s}$ from these regressions are not comparable because the dependent variables are different.)

Finally, in column 4 we report coefficient estimates for a regression where the dependent variable is the Barclay and Smith (1995) measure of debt maturity--debt maturing within three years divided by total debt (DD3/D). Interestingly, firm characteristics enter the "Barclay-Smith" regression more strongly than they enter the regression reported in column 3, but the coefficient on the dummy variable for swap users is close to zero. Thus, it appears that the predictions of our model are rejected by the data if a definition of short-term debt based only on stated loan maturities is used.

This last finding raises the question of which definition of short-term debt is best, a question for which there is no clear answer. As noted earlier, definitions based on stated maturities exclude debt, such as bank loans, for which effective maturities can be much less than stated maturities, especially in those states of the world where agency conflicts such as underinvestment might be heightened. Also, measures based on stated maturities are somewhat problematic to the extent that they reflect remaining time to maturity, and not original maturity. On the other hand, our definition of short-term debt excludes fixed-rate loans that mature in the not too distant future, but in over a year. Our final set of regressions, below, is motivated, in part, by such measurement questions.

\subsection{Underlying Determinants of Swap Position}

As discussed earlier, if debt maturity is measured with a good deal of error, but is closely related to financial characteristics such as size, market-to-book value of assets, etc., then these characteristics might explain more of the variation in firm swap position than our estimates of debt maturity. Likewise, such regressions may prove more informative about the 
determinants of debt maturity than do direct debt maturity regressions to the extent that a firm's swap position is a superior proxy of debt maturity.

Table 7 reports the results of regressions of swap positions on firm financial characteristics (equation (14)), where--following the methodology of the debt structure regressions--firm financial characteristics are interacted with leverage. ${ }^{30}$ Results for two samples of swap users are shown: the first (reported in columns 1 and 2) includes only those firms included in the "structural" swap regressions in table 4, while the second (reported in columns 3 and 4) includes a broader sample of swap users for whom debt maturity data is incomplete.

As anticipated, the adjusted- $\mathrm{R}^{2}$ statistics for the first pair of regressions (columns 1 and 2) are nearly double those for the comparable regressions in table $4 .{ }^{31}$ In addition, the pattern of coefficients is similar to that found in the comparable debt structure regression for swap users (table 5, column 6), though the magnitude and statistical significance of the coefficients are somewhat larger for market-to-book and size, and significantly smaller for asset maturity. ${ }^{32}$ The results in table 7 have a natural interpretation: smaller and more growth-oriented firms (those with higher market-to-book ratios) find long-term debt expensive and, consequently, tend to issue more short-term debt and swap away the greater exposure to interest rate risk; conversely, larger, less growth-oriented, as well as below-investment-grade rated firms issue more long-term debt and are more apt to have a pay-floating swap position.

Underscoring the robustness of these results, the coefficient estimates are little changed when the sample size is doubled (columns 3 and 4) to include firms excluded from our earlier analysis because of incomplete debt maturity data. Overall, these results, in combination with our earlier ones, are consistent with the hypotheses that (1) swaps are closely linked to effective debt maturities, and (2) effective debt maturities, while difficult to

\footnotetext{
${ }^{30}$ The uninteracted intercept is retained here for comparability with table 4 regressions.

${ }^{31}$ This difference is not attributable to the loss of a few observations because of incomplete data on firm characteristics.

${ }^{32}$ The coefficient on leverage in table 7 corresponds to the intercept in table 5. Thus the relevant comparisons are between 0.15 (column 1) or -0.06 (column 2) in table 7 , and 0.48 in table 5 (column 6).
} 
gauge, are determined by firm characteristics such as size, market-to-book value, and ratings.

\section{Conclusion}

The literature on the use of derivatives by nonfinancial corporations has focused largely on why firms care about controlling risk. While this question is surely an important one, and one that has not been fully resolved, our paper represents an attempt to begin researching other important questions. These include: (1) which sources of risk do firms attempt to hedge; and (2) how does hedging influence a firm's other financial decisions?

While our paper provides only preliminary answers to these questions, several findings appear robust, and at a minimum, should motivate further investigation. First, firms appear to differentiate among sources of risk, perhaps according to their ability to accurately measure them. Thus, while in principle it may be desirable to hedge operational exposure to financial price risk, there may be practical barriers to doing so. Second, using derivatives influences debt maturity structure in precisely the manner predicted by theorists. In particular, derivatives permit firms to issue economically efficient levels of short-term debt without exposing themselves to commensurately higher levels of interest rate risk. Lowering the cost of debt is presumably only one of several ways in which the use of derivatives raises firm value. 


\section{References}

Arak, Marcelle, Arturo Estrella, and Laurie Goodman. "Interest Rate Swaps: An Alternative Explanation," Financial Management, vol.17 (Summer 1988), pp. 12-28.

Barclay, Michael and Clifford W. Smith Jr. "The Maturity Structure of Corporate Debt," Journal of Finance, vol. 50 (June 1995), pp. 609-631.

Barnea, Amir, Robert A. Haugen and Lemma W. Senbet. "A Rationale for Debt Maturity Structure and Call Provisions in the Agency Theoretic Framework," Journal of Finance, vol. 35 (December, 1980), pp. 1223-1243.

Bodnar, Gordan M., Gregory S. Hayt, Richard C. Marston, and Charles Smithson. "Wharton Survey of Derivatives Usage by U.S. Non-Financial Firms," Financial Management, vol. 24 (Summer 1995), pp. 104-114.

Demarzo, Peter M. and Darrell Duffie. "Corporate Incentives for Hedging and Hedge Accounting," The Review of Financial Studies, vol. 8 (Fall 1995), pp. 743-771.

Diamond, Douglas W. "Debt Maturity Structure and Liquidity Risk," Quarterly Journal of Economics, vol. 106 (August 1991), pp. 709-737.

Dolde, Walter. "Hedging, Leverage, and Primitive Risk," The Journal of Financial Engineering, vol. 4 (June 1995), pp. 187-216.

Flannery, Mark J. "Asymmetric Information and Risky Debt Maturity Choice," Journal of Finance, vol. 41 (March 1986), pp. 19-37.

Froot, Kenneth A., David S. Scharfstein, and Jeremy Stein. "Risk Management: Coordinating Corporate Investment and Financing Policies," Journal of Finance, vol. 48 (March 1993), pp. 16-29.

Geczy, Christopher, Bernadette A. Minton, and Catherine Schrand. "Why Firms Use Derivatives: Distinguishing Among Existing Theories." Unpublished Working Paper, September, 1995.

Guedes, Jose and Tim Opler. "The Determinants of the Maturity of Corporate Debt Issues." Unpublished Working Paper, December 1995.

Hentschel, Ludger and Clifford W. Smith, Jr. "Risks in Derivative Markets." Unpublished Working Paper, November 1995.

Myers, Stewart C. "Determinants of Corporate Borrowing," Journal of Financial Economics, 
vol. 5 (November 1977), pp. 147-175.

Nance, Deana R., Clifford W. Smith Jr., and Charles W. Smithson. "On the Determinants of Corporate Hedging," Journal of Finance, vol. 48 (March 1993), pp. 267-284.

Phillips, Aaron L. "1995 Derivatives Practices and Instruments Survey," Financial Management, vol. 24 (Summer 1995), pp. 115-125.

Sharpe, Steven A. "Credit Rationing, Concessionary Lending, and Debt Maturity," Journal of Banking and Finance, vol. 15 (December 1991), pp. 581-604.

Smith, Clifford W., Jr., and Rene M. Stulz. "The Determinants of Firms' Hedging Policies," Journal of Financial and Quantitative Analysis, vol. 20 (1985), pp. 391-405.

Smithson, Charles W., Clifford W. Smith, Jr., and D. Sykes Wilford. Managing Financial Risk: A Guide to Derivative Products, Financial Engineering, and Value Maximization. New York, NY: Irwin, 1995.

Stohs, Mark Hoven, and David C. Mauer. "The Determinants of Corporate Debt Maturity Structure," Journal of Business, vol. 69 (July 1996), pp. 279-312.

Titman, Sheridan. "Interest Rate Swaps and Corporate Financing Choices," Journal of Finance, vol. 47 (September 1992), pp. 1503-1516.

Titman, Sheridan and Roberto Wessels. "The Determinants of Capital Structure Choice," Journal of Finance, vol. 43 (March 1988), pp. 1-19.

Tufano, Peter. "Liability Management at General Motors," Harvard Business School, case number 9-293-123, 1993.

Tufano, Peter. "Union Carbide Corporation Interest Rate Risk Management," Harvard Business School, case number N9-294-057, 1994.

Tufano, Peter. "Who Manages Risk? An Empirical Examination of Risk Management Practices in the Gold Mining Industry," Journal of Finance, vol. 51 (September 1996), pp. 1097-1138.

Wall, Larry D. "Interest Rate Swaps in an Agency Theoretic Model With Uncertain Interest Rates," Journal of Banking and Finance, vol. 13 (May 1989), pp. 261-270. 
Table 1

Nonfinancial Firms that Use Interest Rate Derivatives

\author{
Total Number \\ of Firms
}

All Firms

4209

\begin{tabular}{c} 
Users \\
\hline Number $\quad$ Percent of Total
\end{tabular}

384

9.1

\section{By Assets (\$mil)}

$\begin{array}{rrrr}1-100 & 2532 & 26 & 1.0 \\ 100-500 & 961 & 104 & 10.8 \\ 500-1000 & 249 & 59 & 23.7 \\ 1000-2500 & 245 & 80 & 32.7 \\ \text { over } 2500 & 222 & 115 & 51.8\end{array}$

\section{By Rating *}

$\begin{array}{lrrr}\text { Unrated } & 1103 & 155 & 14.1 \\ \text { BB \& Below } & 247 & 72 & 29.1 \\ \text { BBB } & 136 & 49 & 36.0 \\ \text { A \& Above } & 191 & 83 & 43.5\end{array}$

${ }^{*}$ Firms with assets over $\$ 100$ million.

Note: Assets are for fiscal year 1993 or 1994 depending on the most recent data available on the June 1995 Compact Disclosure disk. Ratings describe a firm's senior debt rating and include both publicly-traded and privately-placed debt.

Sources: Compact Disclosure, Compustat, Moody's Industrial Manual, S\&P's Bond Guide, and the Securities Valuation Office of the National Association of Insurance Commissioners. 
Interest Rate Derivatives Used by Non-Financial Firms

\section{Types of Derivatives}

\begin{tabular}{lc} 
Contract & Users \\
\hline Swaps & 350 \\
Caps & 57 \\
Collars & 6 \\
Futures \& & 9 \\
Options & \\
Forward & 6
\end{tabular}

\section{Direction of Swaps}

\begin{tabular}{lc} 
Swaps & Users \\
\hline Pay Fixed & 145 \\
Pay Floating & 68 \\
Both ways & 47 \\
\cline { 2 - 2 } Direction Known & 260 \\
Notional Known & 233
\end{tabular}

Table 2b

Descriptive Statistics for Swap Variables

\begin{tabular}{lllllll} 
Variable & $\min$ & $25 \%$ & $50 \%$ & $75 \%$ & $\max$ & $\mathrm{n}$ \\
\hline Swap1 & -.57 & -.05 & .03 & .08 & 1.05 & 233 \\
Swap2 & -.57 & -.03 & .04 & .09 & 1.34 & 252
\end{tabular}

Note: Swap1 is the notional value of pay-fixed swaps, divided by assets, with pay-floating swaps assigned a negative value. For firms with swaps in both directions, we construct a net notional, equal to pay-fixed notional minus pay-floating notional. Swap2 uses data on caps; caps are treated as pay-fixed swaps.

Source: Compact Disclosure 
Table 3

Descriptive Statistics for Variables in the Swap Regressions (130 Firms)

\begin{tabular}{lccccc} 
Variable & $\min$ & $25 \%$ & $50 \%$ & $75 \%$ & $\max$ \\
\hline Swap1 & -.57 & -.06 & .03 & .10 & .72 \\
Swap2 & -.57 & -.04 & .06 & .13 & 1.34 \\
Short-term debt (f) & 0 & .05 & .18 & .27 & .81 \\
& & & & & \\
$\begin{array}{l}\text { Industry Interest rate } \\
\text { sensitivity of EBITDA }(\beta)\end{array}$ & -2.6 & -.10 & .35 & .58 & 5.66
\end{tabular}

Note: Swap1 and Swap2 are described in table 2. Short-term debt is the sum of debt maturing in one year and floating-rate long-term debt, scaled by assets. Industry $\beta$ is estimated using equation (15) in the text. 
Table 4

\begin{tabular}{|c|c|c|c|c|}
\hline \multirow{3}{*}{$\begin{array}{l}\text { Estimation Method: } \\
\text { Dependent Variable: }\end{array}$} & \multicolumn{4}{|c|}{ Swap Regressions } \\
\hline & \multicolumn{2}{|c|}{ OLS } & \multicolumn{2}{|c|}{ IVa } \\
\hline & Swap1 & Swap2 & Swap1 & Swap2 \\
\hline \multicolumn{5}{|l|}{ Independent Variable } \\
\hline \multirow[t]{2}{*}{ Intercept } & $-.05^{\star}$ & -.02 & $-.08^{* *}$ & -.06 \\
\hline & $(.02)$ & $(.03)$ & $(.03)$ & $(.03)$ \\
\hline \multirow[t]{2}{*}{$f$} & $.50^{\star *}$ & $.56^{\star \star}$ & $.65^{\star *}$ & $.74^{\star *}$ \\
\hline & $(.09)$ & $(.10)$ & $(.12)$ & $(.13)$ \\
\hline \multirow[t]{2}{*}{ Industry $\beta$} & .01 & .01 & .01 & -.01 \\
\hline & $(.01)$ & $(.02)$ & $(.01)$ & $(.02)$ \\
\hline \multirow[t]{2}{*}{ Fiscal Year-end } & .06 & $.11^{* *}$ & .07 & $.12^{\star \star}$ \\
\hline & $(.04)$ & $(.04)$ & $(.04)$ & $(.04)$ \\
\hline Adjusted-R ${ }^{2}$ & .22 & .21 & .20 & .19 \\
\hline No. of Observations & 116 & 130 & 111 & 125 \\
\hline
\end{tabular}

a - The set of instruments for $f$ is the set of regressors included in the short-term debt regressions reported in table 5 . 
Table 5

\section{Regressions for Short-Term Debt Over Assets} Independent Variables Multiplied by Leverage

\begin{tabular}{|c|c|c|c|c|c|c|}
\hline Independent Variable & All & Nonusers & Users & All & Nonusers & Users \\
\hline \multirow[t]{2}{*}{ Intercept } & $.19^{* *}$ & $.21^{* *}$ & $.22^{*}$ & $.54^{\star *}$ & $.58^{\star *}$ & $.48^{* *}$ \\
\hline & $(.04)$ & $(.04)$ & $(.10)$ & $(.04)$ & $(.04)$ & $(.09)$ \\
\hline \multirow[t]{2}{*}{ Log(Sales) } & $-.06^{\star *}$ & $-.05^{\star *}$ & $-.09^{\star *}$ & -.00 & .01 & -.04 \\
\hline & $(.01)$ & $(.01)$ & $(.02)$ & $(.01)$ & $(.01)$ & $(.02)$ \\
\hline \multirow[t]{2}{*}{ Market-to-Book } & .02 & .02 & .08 & .02 & .01 & $.09^{*}$ \\
\hline & .01 & $(.02)$ & $(.05)$ & $(.01)$ & $(.01)$ & $(.04)$ \\
\hline \multirow[t]{2}{*}{ Inv. and Rec./Assets } & $.42^{* *}$ & $.42^{\star \star}$ & $.38^{*}$ & $.21^{\star *}$ & $.19^{\star *}$ & $.30^{*}$ \\
\hline & $(.05)$ & $(.05)$ & $(.16)$ & $(.05)$ & $(.05)$ & $(.13)$ \\
\hline \multicolumn{7}{|l|}{ Rating Dummies: } \\
\hline \multirow[t]{2}{*}{ A \& Above } & & & & $-.32^{\star *}$ & $-.36^{* *}$ & -.24 \\
\hline & & & & $(.06)$ & $(.07)$ & $(.13)$ \\
\hline \multirow[t]{2}{*}{ BBB } & & & & $-.32^{* *}$ & $-.34^{* *}$ & $-.29^{\star *}$ \\
\hline & & & & $(.04)$ & $(.05)$ & $(.08)$ \\
\hline \multirow[t]{2}{*}{ BB \& Below } & & & & $-.41^{* *}$ & $-.41^{* *}$ & $-.41^{* *}$ \\
\hline & & & & $(.02)$ & $(.02)$ & $(.06)$ \\
\hline \multirow[t]{2}{*}{ Industry $\beta$} & $.01^{\star \star}$ & $.01^{* \star}$ & -.01 & .01 & .01 & -.01 \\
\hline & $(.00)$ & $(.00)$ & $(.02)$ & $(.00)$ & $(.00)$ & $(.01)$ \\
\hline \multirow[t]{2}{*}{ Swap User Dummy } & $.15^{\star \star}$ & & & $.12^{\star *}$ & & \\
\hline & $(.03)$ & & & $(.03)$ & & \\
\hline Adjusted-R ${ }^{2}$ & .37 & .37 & .35 & .52 & .52 & .52 \\
\hline No. of Observations & 1108 & 986 & 122 & 1108 & 986 & 122 \\
\hline
\end{tabular}


Table 6

\section{Regressions for Short-Term Debt Alternative Specifications ${ }^{a}$}

\begin{tabular}{|c|c|c|c|c|}
\hline Dependent Variable: & $\mathrm{F} / \mathrm{A}$ & $\mathrm{F} / \mathrm{A}$ & $F / D$ & DD3/D \\
\hline \multicolumn{5}{|l|}{ Independent Variable } \\
\hline \multirow[t]{2}{*}{ Intercept } & $.16^{\star *}$ & .01 & $.54^{* *}$ & $.31^{* *}$ \\
\hline & $(.02)$ & $(.01)$ & $(.04)$ & $(.04)$ \\
\hline \multirow[t]{2}{*}{ Log(Sales) } & $-.01^{*}$ & -.00 & $-.02^{*}$ & $-.03^{* *}$ \\
\hline & $(.00)$ & $(.00)$ & $(.01)$ & $(.01)$ \\
\hline \multirow[t]{2}{*}{ Market-to-Book } & $-.02^{* *}$ & -.00 & -.00 & $.03^{* *}$ \\
\hline & $(.01)$ & $(.00)$ & $(.01)$ & $(.01)$ \\
\hline \multirow[t]{2}{*}{ Inv. and Rec./Assets } & .02 & $.08^{* *}$ & $.25^{\star *}$ & $.49^{* *}$ \\
\hline & $(.02)$ & $(.02)$ & $(.05)$ & $(.05)$ \\
\hline \multicolumn{5}{|l|}{ Rating Dummies: } \\
\hline \multirow[t]{2}{*}{ A \& Above } & $-.09^{\star \star}$ & $-.07^{\star *}$ & $-.34^{\star *}$ & $-.16^{\star *}$ \\
\hline & $(.02)$ & $(.02)$ & $(.04)$ & $(.04)$ \\
\hline \multirow[t]{2}{*}{ BBB } & $-.07^{\star *}$ & $-.09^{* *}$ & $-.36^{\star *}$ & $-.21^{* *}$ \\
\hline & $(.02)$ & $(.01)$ & $(.04)$ & $(.03)$ \\
\hline \multirow[t]{2}{*}{ BB \& Below } & $-.04^{* *}$ & $-.15^{\star \star}$ & $-.38^{* *}$ & $-.28^{* *}$ \\
\hline & $(.01)$ & $(.01)$ & $(.03)$ & $(.03)$ \\
\hline \multirow[t]{2}{*}{ Leverage } & & $.51^{\star *}$ & & \\
\hline & & $(.02)$ & & \\
\hline \multirow[t]{2}{*}{ Industry $\beta$} & .01 & $.01^{*}$ & .01 & .02 \\
\hline & $(.00)$ & $(.00)$ & $(.01)$ & $(.01)$ \\
\hline \multirow[t]{2}{*}{ Swap User Dummy } & $.10^{* *}$ & $.05^{\star *}$ & $.15^{\star *}$ & .01 \\
\hline & $(.02)$ & $(.01)$ & $(.03)$ & $(.03)$ \\
\hline Adjusted- $\mathrm{R}^{2}$ & .08 & .46 & .27 & .27 \\
\hline No. of Observations & 1108 & 1108 & 1108 & 955 \\
\hline
\end{tabular}

a $-F / A$ and F/D are the ratios of short-term debt to total assets and total debt, respectively, where short-term debt is the sum of debt maturing within one year and floating-rate long-term debt. DD3/D is the ratio of debt maturing within three years to total debt. The sample includes swap users and nonusers with more than $\$ 50$ million in assets. The sample size for column 4 is smaller because of missing data for debt maturing within 3 years. 
Table 7

\section{Regressions of Swap Position on Financial Characterisitics}

\begin{tabular}{|c|c|c|c|c|}
\hline Independent Variable & $\begin{array}{l}\text { Swap1 } \\
\text { (1) }\end{array}$ & $\begin{array}{c}\text { Swap2 } \\
(2)\end{array}$ & $\begin{array}{c}\text { Swap1 } \\
\text { (3) }\end{array}$ & $\begin{array}{c}\text { Swap2 } \\
\text { (4) }\end{array}$ \\
\hline \multirow[t]{2}{*}{ Intercept } & -.00 & .06 & -.01 & .02 \\
\hline & $(.03)$ & $(.04)$ & $(.02)$ & $(.02)$ \\
\hline \multirow[t]{2}{*}{ Leverage } & .15 & -.06 & $.21^{*}$ & .11 \\
\hline & $(.14)$ & $(.16)$ & $(.09)$ & $(.10)$ \\
\hline Log(Assets) & $-.08^{* *}$ & $-.09^{\star \star}$ & $-.10^{\star \star}$ & $-.10^{* *}$ \\
\hline *Leverage & $(.03)$ & $(.03)$ & $(.01)$ & $(.02)$ \\
\hline Market-to-Book & $.10^{*}$ & $.21^{\star *}$ & .06 & $.14^{\star *}$ \\
\hline$\star$ Leverage & $(.05)$ & $(.06)$ & $(.03)$ & $(.04)$ \\
\hline Inv. and Rec./Assets & .09 & -.05 & .03 & -.03 \\
\hline$\star$ Leverage & $(.16)$ & $(.19)$ & $(.11)$ & $(.13)$ \\
\hline \multicolumn{5}{|l|}{ Rating Dummies: } \\
\hline A \& Above & -.21 & -.33 & -.06 & -.11 \\
\hline$\star$ Leverage & $(.16)$ & $(.19)$ & $(.11)$ & $(.13)$ \\
\hline BBB & $-.35^{* *}$ & $-.28^{*}$ & $-.29^{* *}$ & $-.27^{* *}$ \\
\hline$\star$ Leverage & $(.10)$ & $(.12)$ & $(.07)$ & $(.08)$ \\
\hline BB \& Below & $-.39^{* *}$ & $-.37^{* *}$ & $-.30^{* *}$ & $-.31^{\star *}$ \\
\hline$\star$ Leverage & $(.08)$ & $(.09)$ & $(.06)$ & $(.06)$ \\
\hline \multirow[t]{2}{*}{ Industry $\beta$} & .01 & .02 & .00 & .01 \\
\hline & $(.01)$ & $(.02)$ & $(.01)$ & $(.01)$ \\
\hline \multirow[t]{2}{*}{ Fiscal Year End } & .15 & $.10^{*}$ & $.06^{*}$ & $.08^{* *}$ \\
\hline & $(.14)$ & $(.04)$ & $(.02)$ & $(.03)$ \\
\hline Adjusted- $R^{2}$ & .36 & .35 & .38 & .33 \\
\hline No. of Observations & 111 & 125 & 222 & 240 \\
\hline
\end{tabular}

Note: Regressions 1 \& 2 are estimated over the same samples included in table 4, less a few observations for which financial characteristics are not available. Regressions $3 \& 4$ are estimated over larger samples that include all firms for which we have the necessary swap data and firm financial characteristics, regardless of whether we have data on debt composition (as was required for the regressions in table 4). 
